\title{
Transpedicular approach for thoracic disc herniations
}

\author{
MARK H. BiLSKY, M.D. \\ Division of Neurosurgery, Department of Surgery, Memorial Sloan-Kettering Cancer Center, New \\ York, New York
}

\begin{abstract}
Object. Patients with symptomatic herniated thoracic discs may require operation for intractable radiculopathy or functionally disabling myelopathy. In the past, laminectomy was the procedure of choice for the treatment of thoracic herniations, but it was found that the approach was associated with an unacceptably high rate of neurological morbidity. Several strategies have been developed to excise the disc without manipulating the spinal cord. The focus of this paper is the transpedicular approach.

Methods. The author retrospectively reviewed the cases of 20 consecutive patients presenting with herniated thoracic discs in whom surgery was performed via a transpedicular approach. Fourteen patients presented with acute myelopathy and six with radiculopathy. Of those with myelopathy six of six regained ambulation and six of seven regained normal bladder function. No patient with myelopathy experienced neurological worsening. In four patients presenting with radiculopathy postoperative pain resolved, and in two it remained unchanged. Three minor complications $(15 \%)$ occurred. No patient suffered postoperative spinal instability-related pain or delayed kyphosis.

Conclusions. As experience accumulates in the use of multiple approaches for the treatment of thoracic disc herniations, the role of each is becoming more clearly defined. The transpedicular approach is most applicable to lateral or centrolateral calcified or soft discs. The more anterior (transthoracic or thoracoscopic) and lateral (costotransversectomy or lateral extracavitary) approaches may be more useful for excision of central calcified discs.
\end{abstract}

KEY WORDS: - transpedicular approach - thoracic spine - intervertebral herniated disc

Herniated thoracic discs are relatively common but rarely require operation. Based on large studies examining radiographic and postmortem studies, the incidence of asymptomatic thoracic disc herniations is 10 to $37 \%, 3,7,31$, $32,38,44,46$ Despite the high prevalence of thoracic disc herniations in the general population, they are rarely symptomatic, and of all operations for disc herniations only $2 \%$ are performed in the thoracic spine

In the 1950s, laminectomy was performed to excise herniated thoracic discs; however, it resulted in greater than $70 \%$ of patients suffering significant postoperative deficits, the majority of whom became paralyzed. ${ }^{2,8,11,18 \text {, }}$ 21,25,28,30 Multiple operative approaches have been developed to treat thoracic disc herniations to overcome the significant neurological morbidity associated with a strictly posterior laminectomy. These approaches are currently categorized as anterior (transthoracic, ,5, $12,15,22,29,34,35,39,41,43$ transsternal, and thoracoscopic ${ }^{10,19,20}$ ), lateral (lateral extracavitary $13,14,16,41,43$ and costotransversectomy $1,6,15,31,37,40)$, and posterolateral (transpedicular ${ }^{4,15,17,23,24,33,36,40}$ and transfacet pedicle sparing ${ }^{41,42}$ ). The authors of numerous surgical series have demonstrated significantly improved neurological outcomes, pain relief, and postoperative spinal stability with these varied approaches compared with laminectomy. Since Patterson and $\mathrm{Arbit}^{33}$ first described the transpedicular approach in 1978, we have used this technique to excise all thoracic disc herniations until recently. Whereas the transpedicular approach is associated with a lower rate of morbidity than the anterior and lateral approaches, these other approaches may be more effective for central calcified discs. ${ }^{41,43}$

\section{CLINICAL MATERIAL AND METHODS}

\section{Patient Population}

Between 1982 and 1992, 20 patients underwent transpedicular thoracic disc excision. This approach was used exclusively in all patients with symptomatic herniated thoracic discs. The median patient age was 47 years (range 25-79 years); there were 10 men and 10 women. Fourteen patients had myelopathy and six radiculopathy. Precipitating events were identified in 13 patients and included falls (three cases), sports-related activity (three cases), heavy lifting (three cases), twisting motion (one case), and the result of being placed in lithotomy position for a gynecological procedure (one case). Neuroimaging studies included computerized tomography myelography in four patients, magnetic resonance imaging in 10 , or both in six.

\section{Surgical Procedure}

The patient is placed in the prone position on radiolucent lateral chest supports. Prior to making the skin incision, the disc level is identified using fluoroscopy in both anteroposterior and lateral projections. An estimation of the vertebral level can be achieved by counting from the 12 th rib, which is readily identified in most patients. A midline linear skin incision is made, extending approximately $4 \mathrm{~cm}$ over the spinous processes at the levels adjacent to the disc herniation. The paraspinous muscles are reflected to expose the medial portion of the transverse processes and facet joint at these levels. Intraoperative 

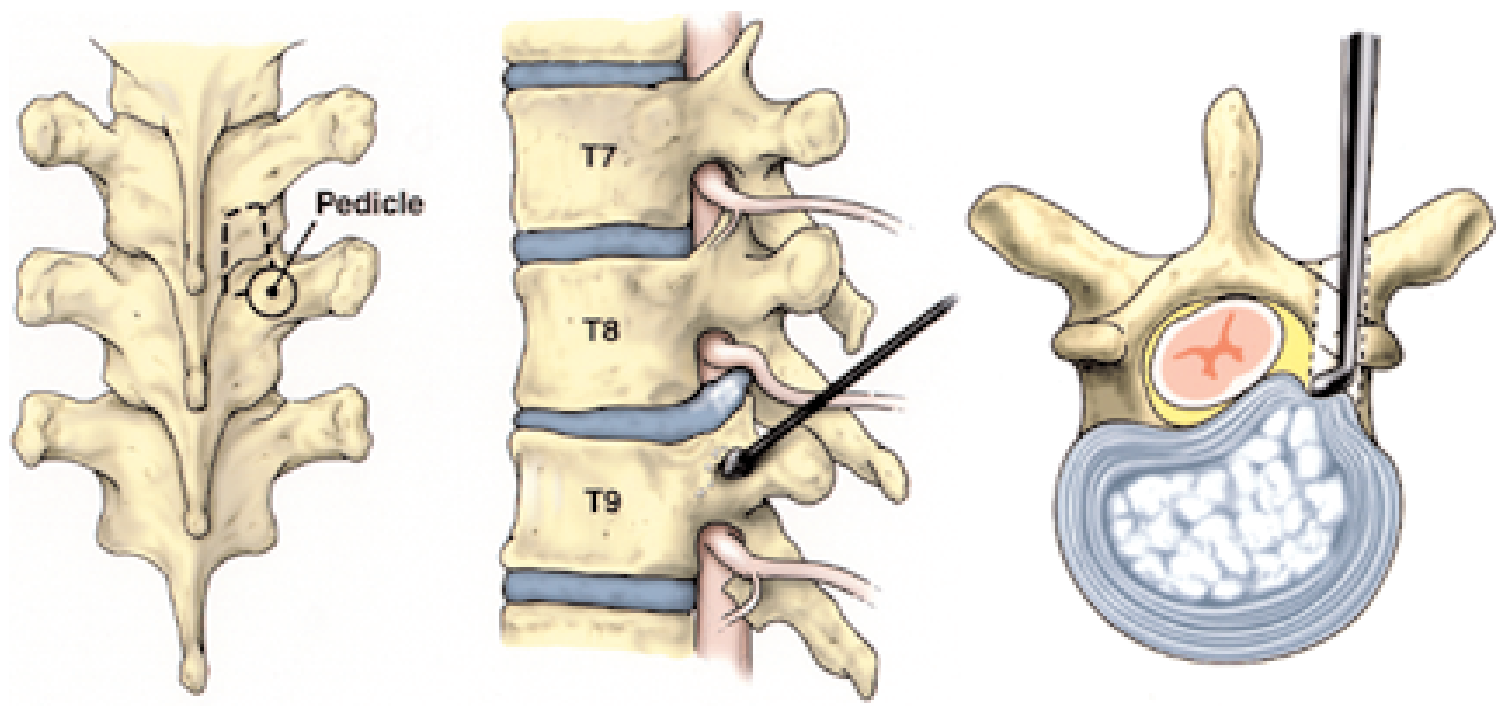

Fig. 1. Diagrams. Left: Anatomical landmark for pedicle (circle) and laminar bone cuts (dotted line). Center: Lateral projection of extent of pedicle resection to the base of the vertebral body. The pedicle of the caudal vertebral body adjacent to the disc space provides exposure for disc exenteration. For example, a T8-9 discectomy requires a T-9 pedicle resection. Right: The disc fragments causing the spinal cord compression are removed.

confirmation of the level is best achieved by fluoroscopic identification of a radiopaque marker placed on the transverse process overlying the pedicle of interest. Spinous process markers are not as reliable.

In a patient with a herniated T8-9 disc, the T-9 pedicle is located adjacent to the disc space. Similar to those in the lumbar spine, the thoracic pedicles are identified by the intersection of the pars interarticularis, transverse process, and lamina (Fig. 1 left). The central cancellous bone of the pedicle (T-9) is removed using a high-speed drill with a side-cutting burr. By using the M-8 burr on the Midas rex drill (Midas, Fort Worth, TX), it has not been necessary to change bits from a cutting to a diamond burr. ${ }^{4}$ The depth of the pedicle resection is established by the transition from the cancellous bone of the pedicle to the posterior cortical bone of the vertebral body (Fig. 1 center). Once the depth of the resection is established, the cortical bone adjacent to the spinal canal is removed using small downbiting curettes. The drill is used to achieve partial superior and inferior facetectomies. The lateral and inferior cortices of the pedicle and lateral facet joints do not need to be resected for adequate exposure. Partial or complete laminectomy is performed if there is significant canal stenosis and/or a large central calcified disc is present. The M-8 burr is used to drill the lamina to the ligamentum flavum, which is resected using tenotomy scissors. A large Kerrison punch should not be used because of the high risk of spinal cord injury.

At the level of the spinal canal, the nerve root is adjacent to the superior pedicle (T-8) and does not need to be retracted. The lateral disc space is incised, and a large cavity is created in the disc space by using curettes and pituitary rongeurs, working in a lateral to medial direction beneath the spinal dura. The disc fragments causing the spinal cord compression are removed using down-biting curettes (Fig. 1 right). The fragments may often be distinguished from normal disc because of their calcification and firmness. Following decompression, right-angle probes and Penfield No. 4 are used to confirm the complete removal of the disc fragments. In performing this transpedicular procedure, intradural fragments have been removed via a transdural or epidural approach.

\section{RESULTS}

The results from the clinical series at New York Hospital have been previously published. ${ }^{4}$

Disc herniations were seen throughout the thoracic spine, most commonly at T8-9 (five patients) and T11-12 (four patients). Surgery revealed 10 calcified discs, and two patients underwent successful removal of intradural fragments.

In 14 patients $(70 \%)$ surgery was performed to resolve myelopathy and in six to treat radiculopathy. Of patients with myelopathy, classic Brown-Séquard syndromes were present in six, transverse spinal cord syndromes in two, and significant symptoms of conus medullaris compression in two. Of six patients who were nonambulatory or ambulatory with assistance preoperatively, all regained independent ambulation postoperatively. Six of seven patients presenting with neurogenic bladders improved postoperatively. One patient with a large central disc herniation experienced transient neurological worsening but regained normal neurological function.

Patients with radiculopathy did not improve as much as those with myelopathy. Four patients improved: two experienced complete resolution of pain and two experienced improved pain relief. The remaining two patients with radiculopathy suffered persistent pain. In one patient repeated neuroimaging demonstrated incomplete disc excision, but the patient declined reoperation.

No patient suffered postoperative instability-related pain. One patient underwent anterior fixation in which polymethylmethacrylate and Steinmann pins were used. Postoperative kyphosis or recurrent disc herniation was not demonstrated in any patient. Complications included 
Staphylococcus aureus deep wound infection (one case), asymptomatic pseudomeningocele (one case), and transient neurological worsening (one case).

\section{DISCUSSION}

Whereas incidental thoracic disc herniations are common, symptomatic ones are rare. Wood, et.al. ${ }^{46}$ prospectively followed 20 patients with 48 thoracic disc herniations; they performed serial magnetic resonance imaging studies and clinical follow-up examinations. All patients remained asymptomatic during a median follow-up period of 26 months. Twenty-one disc herniations were small (0-10\% canal compromise), 20 medium (10-20\% canal compromise), and seven large ( $>20 \%$ canal compromise). Of the 41 small- or medium-sized disc herniations, 37 remained the same or decreased in size and four increased in size. Of the seven large-sized herniations, three remained stable and four decreased in size. Because the great majority of thoracic disc herniations remained stable or decreased in size and because no clinical symptoms developed over time, it is difficult to recommend prophylactic surgery for patients with asymptomatic disc herniations. ${ }^{5,45}$ No predictors currently exist to indicate which patients with incidentally discovered disc herniations will develop symptoms.

Symptomatic disc herniations are often treated surgically. In a review of ten surgical series (238 patients), $5,6,12$, $15,23,26,27,39,40,43$ we found that the indications for operation were myelopathy in $70 \%$ of cases, intractable radiculopathy in $24 \%$ of cases, and back pain in $6 \%$ of cases. These data are similar to those demonstrated in the present series in which $70 \%$ of patients underwent surgery for myelopathy and $30 \%$ for radiculopathy. Asymptomatic myelopathy may be observed, but the surgeon should maintain a low threshold to operate for progressive symptoms or myelopathy with functional impairment. ${ }^{42}$

Neurological outcomes in series in which the transpedicular approach is used are very similar to those obtained using the anterior and lateral approaches. There have been four reported series (Table 1) in which excision of all thoracic disc herniations was performed via a transpedicular approach ${ }^{4,23,24,33}$ and several series in which it has been used for specific indications. ${ }^{15,36,41}$ The transpedicular approach is useful for lateral or centrolateral disc herniations with either a soft or calcified consistency. The transpedicular approach can also be used for central calcified discs, but an anterior or lateral approach improves exposure of the anterior dura mater. In a strictly transpedicular approach, it is difficult to resect a central calcified disc because the dura mater and spinal cord are draped over the mass and disc excision requires manipulation of the spinal dura for exposure. Additionally, the central discs are often adherent to the anterior dura or are intradural, ${ }^{9,47}$ making dissection difficult. We have changed our approach to central calcified disc herniations; we currently use a transthoracic approach. Although there is a steep learning curve associated with disc excision thoracoscopy, the excellent visualization provided by the endoscope and potential reduction in morbidity may make this the approach of choice for central disc herniations. ${ }^{10,20}$

The transfacet pedicle-sparing approach is an excellent posterior approach for lateral soft-disc herniations, as described by Stillerman, et al. ${ }^{41,42}$ Maintaining the pedicle and limiting soft-tissue dissection is thought to improve postoperative spinal stability and reduce back pain. In a review of the series in which the transpedicular approach was used, we did not find any cases of spinal instabilityrelated pain or delayed development of kyphosis. Additionally, the transpedicular approach seemingly provides more space in which to manipulate instruments from a lateral direction and may improve centrolateral disc excision.

In our series complications occurred in $15 \%$ of cases, all of which are considered minor. ${ }^{4}$ Of the 78 patients reported to have undergone transpedicular disc excision in the literature, $, 423,24,33$ there were two major complications (6\%) (paraplegia and discitis) and no additional minor complications. The transpedicular approach avoids the need for extensive muscle dissection, single lung ventilation, and chest tube placement as well as atelectasis associated with the anterior and lateral approaches. Additionally major complications associated with the anterior or lateral approach range from 4 to $13 \%$. These include permanent neurological worsening and discitis. ${ }^{1,5,6,12-16,22 \text {, }}$ $31,34,37,39-41,43$

\section{CONCLUSIONS}

The transpedicular approach is useful for excision of lateral or centrolateral thoracic disc herniations, regardless of whether they are calcified or soft. Central calcified discs may best be approached via an anterior or lateral approach that provides superior exposure to the anterior dura. Complication rates are acceptable, but there is a risk of neurological worsening with all of these approaches.

Great diligence in avoiding application of pressure to the spinal cord as well as the complete excision of all disc material have reduced the rate of neurological morbidity associated with laminectomy.

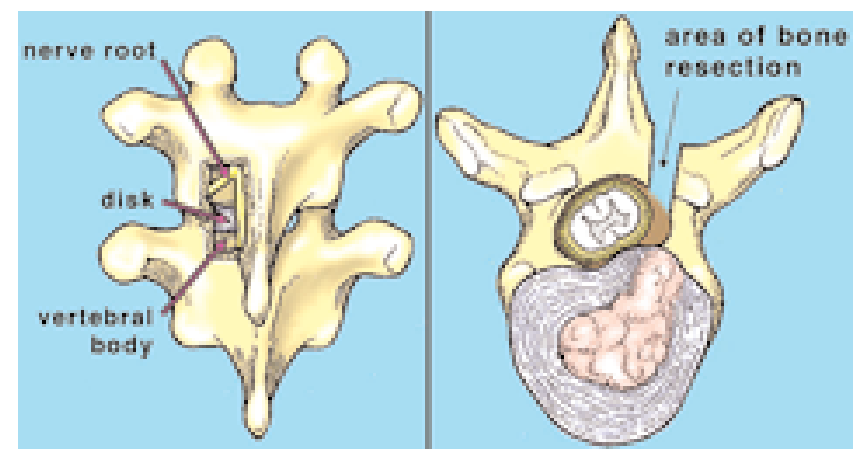




\section{References}

1. Ahlgren BD, Herkowitz HN: A modified posterolateral approach to the thoracic spine. J Spinal Disord 8:69-75, 1995

2. Arseni C, Nash F: Thoracic intervertebral disc protrusion: a clinical study. J Neurosurg 17:418-430, 1960

3. Awwad EE, Martin DS, Smith KR Jr, et al: Asymptomatic versus symptomatic herniated thoracic discs: their frequency and characteristics as detected by computed tomography after myelography. Neurosurgery 28:180-186, 1991

4. Bilsky MH, Patterson RH: Transpedicular approaches, in Benzel EC, Stillerman CB (eds): The Thoracic Spine. St. Louis: Quality Medical, 1999, pp 311-322

5. Blumenkopf B: Thoracic intervertebral disc herniations: diagnostic value of magnetic resonance imaging. Neurosurgery 23:36-40, 1988

6. Bohlman HH, Zdeblick TA: Anterior excision of herniated thoracic discs. J Bone Joint Surg (Am) 70:1038-1047, 1988

7. Brown CW, Deffer PA Jr, Akmakjian J, et al: The natural history of thoracic disc herniation. Spine 17 (Suppl):S97-S102, 1992

8. Chambers AA: Thoracic disc herniation. Semin Roentgenol 23:111-117, 1988

9. Chowdhary UM: Intradural thoracic disc protrusion. Spine 12: 718-719, 1987

10. Connelly CS, Manges PA: Video-assisted thoracoscopic discectomy and fusion. AORN J 67:940-945, 1998

11. Crafoord C, Hiertoon T, Lindblom K, et al: Spinal cord compression caused by a protruded thoracic disc. Report of a case treated with antero-lateral fenestration of the disc. Acta Orthop Scand 28:103-107, 1958

12. Currier BL, Eismont FJ, Green BA: Transthoracic disc excision and fusion for herniated thoracic discs. Spine 19:323-328, 1994

13. Delfini R, Di Lorenzo N, Ciappetta P, et al: Surgical treatment of thoracic disc herniation: a reappraisal of Larson's lateral extracavitary approach. Surg Neurol 45:517-522, 1996

14. Dietze DD Jr, Fessler RG: Thoracic disc herniations. Neurosurg Clin North Am 4:75-90, 1993

15. El-Kalliny M, Tew JM Jr, van Loveren H, et al: Surgical approaches to thoracic disc herniations. Acta Neurochir 111: 22-32, 1991

16. Fujimura Y, Nakamura M, Matsumoto M: Anterior decompression and fusion via the extrapleural approach for thoracic disc herniation causing myelopathy. Keio J Med 46:173-176, 1997

17. Grundy PL, Germon TJ, Gill SS: Transpedicular approaches to cervical uncovertebral osteophytes causing radiculopathy. J Neurosurg 93 (Spine):21-27, 2000

18. Hawk WA: Spinal compression caused by ecchondrosis of the intervertebral fibrocartilage: with a review of the recent literature. Brain 59:204-224, 1936

19. Horowitz MB, Moossy JJ, Julian T, et al: Thoracic discectomy using video assisted thoracoscopy. Spine 19:1082-1086, 1994

20. Huang TJ, Hsu RW, Sum CW, et al: Complications in thoracoscopic spinal surgery: a study of 90 consecutive patients. Surg Endosc 13:346-350, 1999

21. Hulme A: The surgical approach to thoracic intervertebral disc protrusions. J Neurol Neurosurg Psychiatry 23:133-137, 1960

22. Korovessis PG, Stamatakis MV, Baikousis A, et al: Transthoracic disc excision with interbody fusion: 12 patients with symptomatic disc herniation followed for 2-8 years. Acta Orthop Scand Suppl 68 (Suppl 275):12-16, 1997

23. LeRoux PD, Haglund MM, Harris AB: Thoracic disc disease: experience with the transpedicular approach in twenty consecutive patients. Neurosurgery 33:58-66, 1993

24. Levi N, Gjerris F, Dons K: Thoracic disc herniation. Unilateral transpedicular approach in 35 consecutive patients. J Neurosurg 43:37-43, 1999
25. Logue V: Thoracic intervertebral disc prolapse with spinal cord compression. J Neurol Neurosurg Psychiatry 15:227-241, 1952

26. Maiman DJ, Larson SJ, Luck E, et al: Lateral extracavitary approach to the spine for thoracic disc herniation: report of 23 cases. Neurosurgery 14:178-182, 1984

27. McAllister C, Nash F: Protrusion of thoracic intervertebral discs. Acta Neurochir 11:3-33, 1963

28. Mixter WJ, Barr JS: Rupture of the intervertebral disc with involvement of the spinal canal. N Engl J Med 211:210-215, 1934

29. Morgan H, Abood C: Disc herniation at T1-2. Report of four cases and literature review. J Neurosurg 88:148-150, 1998

30. Mueller R: Protrusion of thoracic intervertebral discs with compression of the spinal cord. Acta Med Scand 139:99-104, 1951

31. Oppenheim JS, Rothman AS, Sachdev VP: Thoracic herniated discs: review of the literature and 12 cases. Mt Sinai J Med 60:321-326, 1993

32. Parizel PM, Rodesch G, Baleriaux D, et al: Gd-DTPAenhanced MR in thoracic disc herniations. Neuradiology 31:75-79, 1989

33. Patterson RH Jr, Arbit E: A surgical approach through the pedicle to protruded thoracic discs. J Neurosurg 48:768-772, 1978

34. Perot PL Jr, Munro DD: Transthoracic removal of midline thoracic disc prostrusions causing spinal cord compression. J Neurosurg 31:452-458, 1969

35. Ransohoff JR, Spencer F, Siew F, et al: Transthoracic removal of thoracic disc. Report of three cases. J Neurosurg 31: 459-461, 1969

36. Ridenour TR, Haddad SF, Hitchon PW, et al: Herniated thoracic discs: treatment and outcome. J Spinal Disord 6: 218-224, 1993

37. Rosenbloom SA: Thoracic disc disease and stenosis. Radiol Clin North Am 29:765-775, 1991

38. Ross JS, Perez-Reyes N, Masaryk TJ, et al: Thoracic disc herniation: MR imaging. Radiology 165:511-515, 1987

39. Sekhar LN, Jannetta P: Thoracic disc herniation: operative approaches and results. Neurosurgery 12:303-305, 1983

40. Simpson JM, Silveri CP, Simeone FA, et al: Thoracic disc herniation. Re-evaluation of the posterior approach using a modified costotransversectomy. Spine 18:1872-1877, 1993

41. Stillerman CB, Chen TC, Couldwell WT, et al: Experience in the surgical management of 82 symptomatic herniated thoracic discs and review of the literature. J Neurosurg 88:623-633, 1998

42. Stillerman CB, Chen TC, Couldwell WT, et al: Transfacet pedicle-sparing approach, in Benzel EC, Stillerman CB (eds): The Thoracic Spine. St. Louis: Quality Medical, 1999, pp 338-345

43. Stillerman CB, Weiss MH: Management of thoracic disc disease. Clin Neurosurg 38:325-352, 1992

44. Vanichkachorn JS, Vaccaro AR: Thoracic disk disease: diagnosis and treatment. J Am Acad Orthop Surg 8:159-169, 2000

45. Williams MP, Cherryman GR, Husband JE: Significance of thoracic disc herniation demonstrated by MR imaging. J Comput Assist Tomogr 13:211-214, 1989

46. Wood KB, Blair JM, Aepple DM, et al: The natural history of asymptomatic thoracic disc herniations. Spine 22:525-530, 1997

47. Yildizhan A, Pasoglu A, Okten T, et al: Intradural disc herniations. Pathogenesis, clinical picture, diagnosis and treatment. Acta Neurochir 110:160-165, 1991

Manuscript received September 6, 2000.

Accepted in final form September 14, 2000.

Address reprint requests to: Mark H. Bilsky, M.D., Neurosurgery

Box 71, Memorial Sloan-Kettering Cancer Center, 1275 York Avenue, New York, New York 10021. email: bilskym@mskcc.org. 